\title{
I.OCALIZAÇÃO DO Dipetalonema reconditum (GRASSI, 1890) (Nematoda filariidae) DE Canis familiaris
}

LOCALIZATION OF Diperalonema reconditum (GRASSI, 1890)

(Nemaroda Filariidae) DE Canis familiaris

Edson Barros Figueira de MELL,O'; Antonio Augusto Mendes MAIA² ${ }^{2}$ Leila Alcione Pinheiro de MELLO ${ }^{3}$

RESLMO
Foram necropsiados 24 cães com exame de sangue positivo para microfilarias de Dipetalonema
sp. Veriticou-se que $93,9 \%$ dos parasitos foram encontrados no tecido subcutâneo e $6,1 \%$ nas
visceras. A localização dos helmintos variou com as regimes anatomicas, sendo o tórax o local
de maior freqüência.

UNITERMOS: Dipetalonema reconditum; Cães

\section{INTRODUÇÃO}

NEWTON; WRIGHT ${ }^{15}$ (1956), assinalaram o Dipetalonema reconditum parasitando o tecido subcutânco e o tecido gorduroso peritonial. LINDSEN ${ }^{16}$ (1962); $\operatorname{GUBLER}^{6}$ (1966); FLYNN $^{4}$ (1973); SILVA ${ }^{17}$ (1975) e OLSEN ${ }^{16}$ (1977) dão como "habitat" o tecido subcutâneo. GRASSI; CALANDRUECIO' (1890); NEVEAU-LEMAIRE" (1936) e EUSEBY ${ }^{3}$ (1961) citaram o encontro de forma adulta no tecido adiposo perirrenal. LEVINE" (1968) verificou o parasitismo no tecido conjuntivo subcutâneo c no tecido perirrenal. NELSON ${ }^{13}$ (1962) citou o tecido conjuntivo do pescoço e os espaços faciais. BONAUDI; CRISTOFORI ${ }^{1}$ (1971/1972) assinalaram o encontro no canal deferente e no tecido subcutâneo do escroto. BORCHERT: (1964) citou o encontro no peritônio. SOULSBY ${ }^{18}$ (1968) citou a cavidade do corpo, tecido conjuntivo subcutâneo e tecido intramuscular. L.INDSEY ${ }^{10}$ ( 1962 ) encontrou $53 \%$ dos parasitas na carcaça animal posteriormente ao diafragma, $27.7 \%$ na carcaça anteriormente ao diafragma e $19,3 \%$ nos membros c pele dos membros. KORKEJIAN; EISSON ${ }^{R}$ (1978), encontraram helmintos adultos na região do tronco (pescoço ao sacro) e nos membros posteriores.

Devido à grande diversidade de informações a respeito da localização do Dipetalonema reconditum, foi delineado o presente trabalho que teve por objetivo estudar a localização dos vermes adultos em animais portadores de microfilarias de Dipetalonema sp no sangue circulante.

\section{MATERIAL E MÉTODO}

Foram utilizados 24 cães de uma cidade de São Paulo, sendo 19 machos e 5 fêmeas, todos com exame de sangue positivo para microfilaria de Dipetalonema sp, segundo as técnicas de $\mathrm{KNOTT}^{7}$ (1939) e de MELLO; MAUGE'2 (1983).

Os animais foram anestesiados com Pentobarbital sódico em solução a $3 \%$ por via endovenosa, na dose de $1 \mathrm{ml}$ por quilo de peso vivo e a seguir procedeu-se sangria branca pela secção da artéria carótida. Após o sacrifício os animais foram dissecados retirando-se toda pele, sendo a carcaça e a pele divididas segundo as regimes anatômicas. As vísceras também foraın individualizadas para exame. A pesquisa dos vermes adultos foi realizada segundo a fase de imersão do método MELLO; CAMPOS ${ }^{11}$ (1974), modificada, pois após duas horas de aplicação do método tradicional a temperatura foi elevada para $60^{\circ} \mathrm{C}$ por mais duas horas.

\section{DISCUSSÃO}

LINDSEY ${ }^{10}$ (1962) encontrou a maior porcentagem de Dipetalonema reconditum na carcaça localizada posteriormente ao diafragma - $53 \%$ e nós $23,7 \%$.

Encontramos a maior porcentagem de parasitos na carcaça anterior ao diafragma $53,3 \%$ contra $27,7 \%$ de LINDSEY $^{10}$ (1962). 


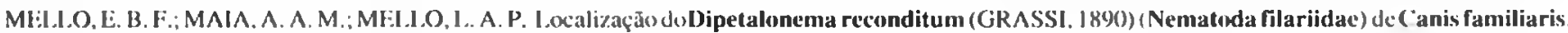
Braz. J. vet. Kes. anim. Sci., Säo Paulo, v. 31, n.1., p. 9.11. 1994.

Quantoaos membros anteriores e posteriores houvesemelhança nos resultados; LINDSEY'1") (1962) - 19,3\% c nós 23\%.

LINDSEY ${ }^{10}$ (1962); GUBLER ${ }^{6}$ (1966); FLYNN ${ }^{4}$ (1973); SILVA $^{17}$ (1975) e OLSEN ${ }^{16}$ (1977) dão como local de parasitismo o tecido conjuntivo subcutâneo; considerandose a carcaça após a retirada da pele também como tecido subcutâneo, neste local encontramos $93,9 \%$ dos parasitos, o que mostra ser de fato este tecido o local mais importante deste parasitismo, variando apenas com a região anatômica.

\section{RESULTADOS}

Dos 24 cães necropsiados a presença de vermes adultos foi registrada em 14 individuos, com um total de 148 exemplares com a seguinte distribuição: tecido subcutâneo 139 parasitos, destes, $95(68,34 \%)$ foram encontrados na carcaça sem a pele c $44(31,65 \%)$ no tecido conjuntivo subcutâneo da pele. Nas vísceras foram observados $9(6,1 \%)$ parasitos.

A localização por região anatômica foi:

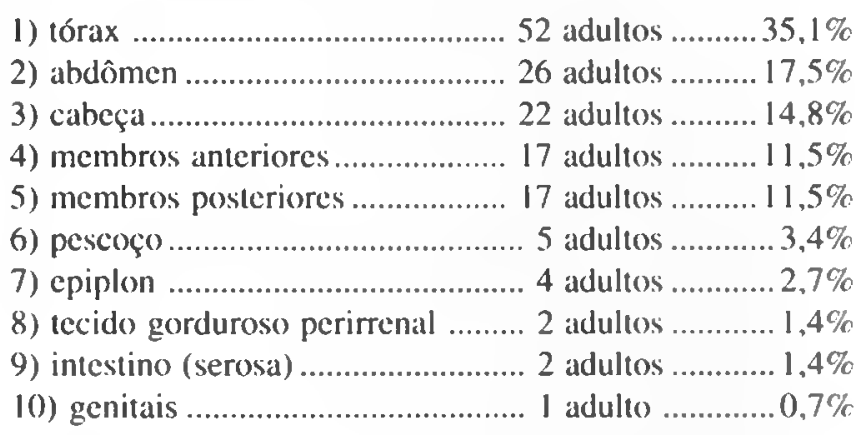

No figado, pulmão, coração e olhos nada foi encontrado.

\section{SUMMARY}

The necropsy of 24 dogs with positive blood scrum test for Dipetalonema sp microfilarias demonstrated that $93.9 \%$ of the parasites were located in the subcutaneous tissue and $6.1 \%$ in general visceral organs. The helminths were localized in different anatomical regions, the chest was found with the highest frequency.

UNITERMS: Dipetalonema reconditum: Dogs

\section{REFERÊNCIAS BIBLIOGRÁFICAS}

01-BONAUDI, R.: CRISTOFORI, F. Inconsueta localizaraione di nematodi nel dotto deferente di un cane. Ann. Fac. Med. Vet. Torino. v.19, p.121-5, $1971 / 1972$.

(02-BORCHERT. A. Parasitologia veterinária. 3.ed. Zaragoza, Acribia, 1964.

0.3-EUSEBY, J. Les maladies vermineuses des animaux domestiques et leurs incidences sur la pathologie humaine. Paris, Vigot Frères, 1961.

04-FLYNN, R.J. Parasites of laboratory animals. Ames, Iowa State University Press, 1973.
05-GRASSI, B.; CALANDRUECIO, S. Ueber hematozoon lewis: entwickelungscyklus einer filaria (filaria recondita Grassi) des hundes.Zhl. Bakt. Parasitenkd., v.7, p. $18-26,1890$.

06-GUBLER, D.J. A comparative study on the distribution, incidence and periodicity of the canine filarial worms Dirofilaria immitis leidy and Dipetalonema reconditum. J. Med. Entomol., v.3. p. 159-67, 1966.

07-KNOTT, J. A method for making microfilarial surveys on day blood. Trans. Roy. Soc. Trop. Med. Hyg., v.33, p.191-6, 1939.

08-KORKEJIAN, A.; EDSON, J.F.B. Studies on naturally occurring filarial infections in dogs in Lebanon. Ann. Trop. Med. Parasitol., v.72, p.65-78, 1978. 
MELLO, E. B. F.; MAIA, A. A. M ; MELLO, L. A. P. I.ccaliyaçāo dolDipetalonema reconditum (GRASSI, I890)(Nematoda filariidae) de Canis faniliaris Braz. J. vet. Res. anim. Sci., São Paulo. v. 31, n. I, p. 9- I1, 1994.

09-LEVINE, N.D. Nematode parasites of domestic animals and of man. Minneapolis, Burgess, 1968.

10-LINDSEY. J.R. Diagnosis of filarial infections in dogs. Il. confirmation of microfilarial identifications. J. Parasitol., v.48, p.321-6, 1962.

11-MELLO, E.B.F.; CAMPOS, M.S. Nova técnica de coleta de helmintos parasitas intestinais. Arq. Inst. Biol., São Paulo, v.41, p.201-6, 1974.

12-MELLO, E.B.F.; MAUGE, G.C. Nova lécnica para diagnóstico e contagem de microfilarias. In: CONGRESSOS INTEGRADOS DE PARASITOLOGIA, São Paulo, 1983. p.l15.

13-NELSON. G.S.Dipetonema reconditum (GRASSI, 1889) from the dog whith a note on its development in the fleo, Ctenocephalides felis and Iouse, Heterodoxus spinizer. J. Helminthol., v.36, p.297-308, 1962
14-NEVEU-LEMAIRE, M.Traité d'helminthologie medicale et vétérinaire. Paris, Vigot Fréres, 1936.

15-NEWTON, W.L.; WRIGHT, W.H. The occurrence of a dog filariid other then Dirofilarie immitis in the United States. J. Parasitol., v.42, p.246-58, 1956.

16-OLSLN, O.W. Parasitologia animal. Barcelona, Acdos, 1977. v.2.

17-SILVA. A.A.J. Dipetalonema reconditum (GRASSI, 1890) em um cão de Salvador, Bahia (Nematoda fïlarioidea). Atas Soc. Biol. R. Janeiro, v. 17, p. 117 9, 1975.

18-SOLLSBY, E.J.L. Helminths, arthropods and protozoa of domesticated animals. 6.ed. London, Tindall and Cassell, 1968

Recebido para publicação em 08/09/92 Aprovado para publicação em 02/07/93 